\title{
Redes de poder durante el "Estado Novo" brasileño: los intelectuales autoritarios y la constelación Capanema
}

\author{
Power networks during the brazilian "Estado Novo": authoritarian \\ intellectuals and Capanema constellation
}

\author{
Gabriela De Lima Grecco \\ Departamento de Historia Contemporánea \\ (Universidad Autónoma de Madrid), España \\ gabriela.lima@uam.es
}

\section{Resumen}

Este artículo tiene por objetivo analizar las redes que existieron entre algunas figuras del sector intelectual brasileño y su rol al interior del Estado Novo (1937-1945). Para ello, se examinan las relaciones personales, profesionales e ideológicas entre este grupo de escritores, así como sus vínculos con los órganos estatales, y con el espacio público que ocuparon. Se busca de este modo comprender su rol dentro de la estructura de poder, y desentrañar sus mecanismos de adaptación frente al conjunto de actores que convergieron en la construcción de un proyecto de Estado. Se entiende que existió una red de relaciones entre los proyectos de la política cultural oficial y estos intelectuales, cuya colaboración confirió una cohesión a la misma mediante su participación.

\section{Palabras claves}

Brasil, Estado Novo, Intelectuales, Redes, Burocracia.

\begin{abstract}
This article attempts to analyze the networks that existed among some intellectual figures of Brazilian industry and the place occupied within the state structure during the Estado Novo (1937-1945). To do this, through the analysis of primary sources, personal, professional and ideological ties of this group of writers are discussed, and the relationship they established with state bodies, and public space they occupied within the state apparatus. It seeks to understand the role played by men and women of letters within the power structure, and unravel what were your mechanisms of adaptation that took place in a large group of actors who converged on the building of a state project.
\end{abstract}

\section{Key words}

Brazil, Estado Novo, Intellectuals, Networks, Bureaucracy.

Esta obra está sujeta a la Licencia Reconocimiento-NoComercial-Compartirlgual 4.0 Internacional de Creative Commons. http://creativecommons.org/licenses/by-nc-sa/4.0/ (cc)) EY-NC-sa 


\section{Introducción}

Todos los hombres son intelectuales, podríamos decir, pero no todos los hombres tienen en la sociedad la función de intelectual.

\section{Antonio Gramsci}

Durante el periodo comprendido entre 1930 y 1954, el escenario político brasileño fue dominado por la figura de Getulio Dornelles Vargas. El término Estado Novo se refiere a la etapa histórica que empezó el 10 de noviembre de 1937, cuando se puso en marcha la disolución del Congreso Nacional y se impuso una nueva Constitución. Este acontecimiento dio inicio a una nueva etapa en la historia brasileña, en que se implementó un régimen autoritario que apeló de manera constante a las masas, y cuya misión fue el fortalecimiento del poder coactivo estatal y el desarrollo de formas de control de las diferentes esferas de la vida social. Vargas buscó la continuidad de una política marcadamente autoritaria, favorecida por la creación de órganos y ministerios centralizadores, la concentración de poder en el Ejecutivo, la disolución de partidos y la elaboración de discursos legitimadores desde el Estado. Para la consolidación de un régimen de estas características, se necesitó contar con la colaboración de grupos de intelectuales que pudiesen ejercer una influencia importante dentro del régimen, y que compartiesen argumentos políticos e ideológicos para poner en marcha un nuevo discurso y una nueva política cultural.

El concepto de intelectual utilizado en este trabajo corresponde al de hombre de pensamiento y acción. Mientras que la visión clásica sobre los intelectuales ha sido siempre relacionada con la acción teórica, a partir de finales del siglo XIX, se produjo un cambio sustancial: los intelectuales pasaron a contribuir al juego de las pasiones políticas. ${ }^{1}$ De este modo se tornaron agentes políticos, capaces de intervenir en los asuntos sociales por medio de su participación en los aparatos ideológicos del Estado. ${ }^{2}$ En particular, trataremos de analizar las redes ${ }^{3}$

\footnotetext{
1 Julien Benda. La traición de los intelectuales. Argentina, Efece ediciones, 1974.

2 Para Althusser los aparatos ideológicos del Estado se diferencian de los aparatos del Estado por funcionar masivamente con la ideología como forma predominante, capaz de ser un poder represivo simbólico. Louis Althusser. Ideología y aparatos ideológicos del estado. Freud y Lacon. Buenos Aires, Nueva Visión, 1988.

${ }^{3}$ Según Böttcher, Hausberger e Ibarra "el concepto de red sirve para describir la asociación de un grupo de personas basada en relaciones de confianza y en un intercambio continuo de servicios o favores dentro de un sistema de reciprocidad. La red se extiende sobre todo, horizontalmente, pero adquiere también una dimensión vertical, o en otras palabras, una jerarquización, así que sus relaciones de reciprocidad muchas veces son asimétricas". Nilolaus Bottcher, Bernd Hausberger \& Antonio Ibarra (coords.). Redes y negocios globales en el mundo ibérico, siglos XVI-XVIII. Madrid, Iberoamericana, 2011.
} 
que existieron entre algunas figuras del sector intelectual brasileño y el lugar que ocuparon dentro de la estructura estatal. Para ello, se examinarán las relaciones personales que tuvieron lugar entre los escritores a través del análisis de cartas, prontuarios y del espacio público que ellos ocuparon. La selección de los sujetos para este estudio fue determinada por la documentación disponible en los fondos del CPDOC/FGV -disponible en los fondos del Centro de Pesquisa e Documentação de Historia Contemporanea do Brasil de la Fundação Getulio Vargas- y del Archivo Público de Sao Paulo, y por estudios ya consagrados como los de Sergio Miceli, Intelectuais à brasileira, y de la obra organizada por Heloisa Bomeny, Constelação Capanema.

Con el objetivo de dar un tratamiento sistemático a las fuentes y a los datos históricos a partir de un prisma crítico, se busca comprender el rol del régimen y sus mecanismos de control frente al conjunto de actores que convergieron en la construcción de un proyecto de Estado. Los ideólogos del Estado Novo tenían una preocupación por demostrar que el régimen se sostenía en una base cultural sólida y que respondía al empeño de renovación nacional. En este sentido, existió una red de relaciones que conectaban los proyectos de la política cultural con los intelectuales, en especial aquellos formulados por el ministro de Educación, Gustavo Capanema, cuya colaboración confirió una cohesión a la cultura oficial. De esta manera, los escritores participaron activamente en el proyecto pedagógicoliterario oficial, en una simbiosis clara entre praxis política y literaria.

\section{La política cultural y el papel de los escritores}

Las relaciones entre el poder político y los intelectuales configuran un tema de gran relevancia, ya que su estudio nos fuerza a adentrarnos en los complejos vínculos que se construyen entre el campo de la política y el resto de campos sociales. ${ }^{4}$ Por ello, el concepto de red constituye un instrumento útil para producir nuevas perspectivas y profundizar los conocimientos sobre las conexiones existentes entre los intelectuales y el ámbito político. En este sentido, durante el Estado Novo en Brasil, los literatos tuvieron un papel destacado como agentes capaces de negociar ${ }^{5}$ con el gobierno. Cierto es que hubo una profunda inserción de este grupo social en la organización político-ideológica del régimen a través de la creación de redes formales e informales dentro de las estructuras administrativas del poder central, capaces de crear canales de negociación con las autoridades políticas.

\footnotetext{
4 Juan Pan-Montojo (ed.). "Poderes privados y recursos públicos”. Ayer; n66. Madrid, 2007.

5 Con el término negociación, Homi K. Bhabha en $O$ local da cultura, llama la atención hacia el acto discursivo, en el cual las instancias contradictorias y antagónicas interactúan, abriendo espacios híbridos y de lucha sin, para eso, fundamentarse en un discurso redentor.

Es a partir de esta idea que Bhabha sugiere que siempre existieron estrategias textuales y de representación que, a menudo, a través de la negociación con las autoridades políticas, crean espacios por donde circular. Homi Bhabha. O local da cultura. Belo Horizonte, UFMG, 1998.
} 


\section{Gabriela De Lima Grecco}

Los intelectuales participaron de forma activa en movimientos organizados durante los años veinte y treinta como estrategia para adentrarse en los espacios y debates políticos y culturales. Estos puntos de encuentro, como cafés literarios, tertulias y la Semana de Arte Moderna, sirvieron como espacios de cambio y construcción de una nueva identidad. Si la construcción de una red depende del contacto entre sus integrantes a lo largo del tiempo, esta convivencia irá cambiando, y muchos agentes irán entrando y saliendo, dado el carácter dinámico y variable de la red. Estas redes de intelectuales fueron construyéndose a lo largo de los años y de los distintos procesos históricos, como el movimiento modernista, la crisis del sistema liberal de la República Vieja, y la Revolución de 30. Todos ellos contribuyeron a la construcción del Estado Novo, y los intelectuales se vieron a sí mismos como sujetos destacados para el desarrollo de las instituciones estatales. ${ }^{6}$

Durante el primer tercio del siglo XX se dieron las condiciones sociohistóricas para la profesionalización del trabajo intelectual, sobre todo respecto a su forma literaria. En este sentido, como señala Miceli ${ }^{7}$, el campo intelectual ${ }^{8}$ pudo desplegarse de forma más o menos autónoma. En el contexto del nuevo régimen, los escritores contribuyeron de forma destacada en el complejo sistema de dominación, y su participación asumió formas muy complejas dentro de la red institucional. En esta lucha política -a la vez, teórica y práctica- por conservar o transformar las categorías de percepción del mundo ${ }^{9}$ se estructuraron diferentes tipos de relaciones: mientras el poeta Carlos Drummond de Andrade sirvió al Estado pero no se sometió intelectualmente a la ideología oficial (ejemplo de eso fue la publicación de su obra Sentimento do mundo), Cassiano Ricardo dio apoyo a través de su palabra y su acción política. ${ }^{10}$

La creación de nuevos frentes de colaboración con el sistema de poder, reflejados en el rol del Estado como principal inversor y difusor cultural, supuso desde luego un elemento nuevo en el sistema político. De ahí que el artículo 128 de la nueva Constitución confiriese al Estado el deber de contribuir directa o indirectamente al desarrollo de la cultura del país y, para ello, se debía favorecer la creación de innumerables órganos burocráticos como agencias, institutos, consejos o entidades autárquicas que centralizasen las diferentes demandas de la sociedad. El 1 de julio de 1938, Vargas estableció, a través del Decreto-ley n 526, el Consejo Nacional de Cultura, encargado de coordinar todas las actividades relativas al desarrollo de la cultura nacional, bajo supervisión del Ministerio de Gustavo Capanema. A partir del mismo se promovió, entre otras cosas, el desarrollo de la

\footnotetext{
${ }^{6}$ Vid al respecto: Tatyana Amaral de Maia. Os cardeais da cultura nacional. São Paulo, Itau Cultura, 2012.

${ }^{7}$ Sergio Miceli. Intelectuais à brasileira. São Paulo, Companhia das Letras, 2001; pág. 16.

${ }^{8}$ Vid. al respecto Pierre Bourdieu. A economía das trocas simbólicas. Sao Paulo, Editora Perspectiva, 1982; págs.183-202.

${ }_{9}^{9}$ Pierre Bourdieu. O poder simbólico. Rio de Janeiro, Bertrand Brasil, 2010.

${ }^{10}$ Candido ápud Sergio Miceli. Intelectuais à brasileira. São Paulo, Companhia das Letras, 2001; pág. 74.
} 
producción literaria, filosófica, científica y artística ${ }^{11}$ de cara a conducir un proyecto cultural nacionalista, en el cual «las plumas oficiales» se mostraron agentes imprescindibles para su construcción.

Dentro de esta política, el régimen apostó por un trabajo de cooptación y, a partir de ello, la ilustración brasileña pasó a participar en la construcción de la cultura oficial. La defensa del papel de los intelectuales como actores-impulsores del proceso de cambio social fue un componente predominante del proyecto de Estado. Para ello las redes se estructuraron para cohesionar a los grupos políticos y establecer una visión compartida del mundo. Así se configuró la gran ambigüedad y complejidad del régimen getulista, que incorporó a intelectuales de distintas tendencias ideológicas -los modernistas, comunistas, liberales o integralistas- que trabajaron mano a mano en favor de la construcción de un proyecto de Estado nacional. Asimismo, esta heterogeneidad puede ser explicada por las redes formadas en torno a los diferentes núcleos de intelectuales: por un lado, los dipeanos y los integralistas; y por el otro, los de la constelación Capanema. De este modo, en un esfuerzo de creación de una cultura literaria nacionalista se consolidó una relación directa entre los hombres y mujeres de letras y la política: así, las artes y la política se tornaron inseparables como señala Randal Johnson. ${ }^{12}$

Por otra parte, tal y como observa la historiadora De Castro Gomes, ${ }^{13}$ el Estado, y más específicamente el ministro Capanema, utilizó los «recursos» de los que disponía para rodearse de intelectuales a los que otorgó una posición clave y estratégica para llevar a cabo ciertas políticas públicas. Por esta razón, la labor de cooptación se tradujo en un mecanismo de doble vía: no solo los intelectuales tuvieron interés y buscaron participar del aparato cultural del Estado, sino que también las autoridades gubernamentales «pidieron» la cooptación de algunos de ellos. De ahí la importancia del llamado poeta-de-gabinete como retrato de esta nueva etapa de la política brasileña, durante la cual los intelectuales se sumergieron en la dinámica burocrática del Estado a través de la construcción de múltiples canales de conexión entre lo público y los grupos formados por escritores.

\section{Los escritores autoritarios: los dipeanos y los integralistas}

El Departamento de Imprensa e Propaganda (en adelante DIP) fue creado a través del Decreto-ley presidencial $\mathrm{n}^{\circ} 1.915$, el 27 de diciembre de 1939 y su objetivo fue el monopolio de la prensa y del libro, así como la coordinación de la comunicación social del Estado Novo. Estuvo subordinado a la persona de Getulio Vargas y era él quien nombraba directamente todos los cargos de confianza. Fue

\footnotetext{
11 Daryle Williams. "Gustavo Capanema, o ministro da Cultura". Angela Maria de Castro Gomes (org.). Capanema: o ministro e seu ministério. Rio de Janeiro, FGV, 2000; págs. 251-269.

12 Randal Johnson. "A Dinâmica do Campo Literário Brasileiro". Revista USP. São Paulo; $n^{\circ} 26$, junho/agosto, 1995; pág. 161.

13 Angela Maria de Castro Gomes. O ministro e sua correspondência..., Op. Cit, págs.13-48.
} 


\section{Gabriela De Lima Grecco}

así como designó a Lourival Fontes -escritor de la revista Hierarquia, admirador del Duce, y conocido como el «Goebbels tupiniquim»- como director general. Asimismo, el DIP buscó consolidar un auténtico control alrededor de todo el territorio nacional, creando para ello los Departamentos Estaduales de Imprenta y Propaganda (DEIP's), que nacieron ya subordinados directamente al propio DIP. Así, alrededor de la figura de Lourival Fontes se formó un complejo cuadro de intelectuales, los dipeanos, que realizaron una labor de control y censura en el campo cultural. Sin embargo, este conjunto de intelectuales que pasaron a formar una red en torno a Fontes ya se había organizado anteriormente, ${ }^{14}$ más concretamente durante la década de veinte, a través del periódico Correio Paulistano $^{15}$ (órgano oficial del Partido Republicano Paulista) y en torno a la celebración de la Semana de Arte Moderna.

Los directores generales del DEIP de Sao Paulo, Candido Mota Filho, Cassiano Ricardo y Menotti Del Picchia, se constituyeron como los modernistas de derechas que participaron de la Semana de Arte Moderna. Celebrada en la ciudad de Sao Paulo en febrero de 1922, representó el acto inaugural del modernismo brasileño. Como despliegue en la Semana, surgieron dos movimientos modernistas, el Pau-Brasil/ y el Verde-Amarelo. Cassiano, Picchia, Candido, junto al futuro integralista Plinio Salgado, fueron los principales representantes del movimiento verde-amarelo. En mayo de 1929, el grupo publicó el Manifesto do Verde-Amarelo, donde expusieron los objetivos del movimiento artístico: "tenemos que construir esta gran nación, integrando la Patria Común a todas las expresiones históricas, étnicas, sociales, religiosas y políticas. Por la fuerza centrípeta del elemento tupi". ${ }^{16}$

Podemos trazar, por lo tanto, el camino que llevó a este conjunto de intelectuales modernistas a estrechar sus relaciones y a conformar una red. Desde luego, a través de esta red de camaradería y de compañerismo ideológico-artístico, estos actores sociales aprovecharon la estructura burocrática estatal, de acuerdo a sus objetivos materiales o de seguridad, siendo absorbidos por el régimen varguista. Por otro lado, tal y como señala Williams (2001), al absorber el régimen de Vargas a los artistas modernistas, también absorbió su proyecto modernista. Es decir, Vargas utilizó un conjunto de fundamentos pertenecientes a los verdeamarelos (como la visión chauvinista, su idea de nación y el concepto de brasilidad) $\mathrm{y}$, por consiguiente, los intelectuales modernistas pasaron a ser considerados como los individuos más capacitados para reconocer la verdadera cultura nacional de Brasil.

\footnotetext{
${ }^{14}$ Otra manera de identificar las conexiones entre Lourival Fontes y estos intelectuales es a través de las diferentes relaciones anteriores al ingreso de Cassiano, Picchia o Mota en la burocracia del Estado. Por ejemplo, Cassiano Ricardo fue designado por Fontes para la elaboración de una revista governista, Brasil Novo, publicada por primera vez en 1938. (María José Campos. "Cassiano Ricardo e o "mito da democracia racial": uma versão modernista em movimento". Revista USP. São Paulo, 2005-2006; pág. 153).

15 Menotti del Picchia fue redactor-jefe del periódico, donde también trabajó Plinio Salgado y Cassiano Ricardo.

16 Picchia ápud Jorge Schwartz. Vanguardas Latino-Americanas: polêmicas, manifestos e textos críticos. São Paulo, EDUSP, 1995; pág. 148.
} 
El dipeano Cassiano Ricardo, por ejemplo, fue, además de director general del DEIP paulista, censor-jefe -cargo otorgado a través de la ley 12.486-. Su sueldo anual era de $16.800 \$ 000$ cruceros, $^{17}$ valor bastante alto si se lo compara, por ejemplo, con la labor de un revisor en una empresa periodística, que ganaba cerca de $7.200 \$ 000$ cruceros durante los años cuarenta. ${ }^{18}$ Considerando estas condiciones, es evidente que los verde-amarelos gozaran de bastante prestigio y supieron ejercer su influencia dentro del Estado varguista.

Durante la década de los años treinta el grupo verde-amarelo se bifurcó en dos movimientos distintos. Plinio Salgado fue quien rompió con el grupo original al idear la construcción de un movimiento más radical y de pretensiones fascistas, la Acción Integralista Brasileña (en adelante AIB). Por otro lado, cabe señalar que Plinio mantuvo una relación muy estrecha con Vargas, tal y como se manifiesta a través de la intensa correspondencia entre ellos. En términos de principios doctrinales, el Integralismo y el poder central compartían muchas propuestas comunes (como el énfasis otorgado al culto a la Patria, a las prácticas cívicas y a las políticas de nacionalismo exacerbado, el rechazo al liberalismo y al sufragio universal, la identificación con un Estado fuerte y corporativista, la restricción a las autonomías estatales y la necesidad de una regulación de la cultura). De hecho, el 7 de septiembre de 1941, Plinio Salgado señalaba en una carta a los integralistas que los fundamentos ideológicos de la doctrina del Movimiento eran los mismos que habían inspirado a la Constitución de 1937, afirmando que "jamás hubo divergencias respecto a las bases doctrinarias entre los integralistas y el régimen". 19

Sin embargo, esta relación no gozaba de mucha estabilidad. Plinio estaba convencido de que Vargas transformaría el Integralismo en la base doctrinaria del nuevo régimen y que le otorgaría la dirección del Ministerio de Educación. Pero fue todo lo contrario. Para encubrir la inminente ruptura, Getulio negoció, tras la extinción de las formaciones políticas, la transformación de la AIB en Asociación Cultural (con el nombre de Associação Brasileira de Cultura), garantizando la supervivencia y el apoyo del movimiento. No obstante ello, poco después canceló el registro de la Asociación, y prohibió cualquier manifestación o publicación integralista. Ello llevó a que la ruptura entre el ejecutivo y los fascistas caboclos fuese inminente, culminando en un intento de golpe de Estado en mayo de 1938. Tras el putsch, diversos integrantes integralistas fueron detenidos, y Plinio se exilió en Portugal.

Todo ello, no obstante, no impidió que en el seno de la red que se construyó en torno a los integralistas y el poder estatal se delimitase una nueva relación de colaboración. Aunque se presentaron situaciones de extrema conflictividad y fricciones incómodas, fue posible reactivar un proceso de negociación, cuya consecuencia fue la incorporación de muchos integralistas a la burocracia

\footnotetext{
${ }^{17}$ Archivo Público de Sao Paulo (en adelante APSP), Código 7378.

${ }^{18}$ APSP, Código 20K13523.

${ }^{19}$ Archivo CPDOC/FGV: FC 38.05.12 tp.
} 


\section{Gabriela De Lima Grecco}

estadonovista. Un claro ejemplo es el caso del jurista Miguel Reale -uno de los principales líderes e ideólogos integralistas-, quien en 1942 obtuvo el cargo de Consejero del Departamento Administrativo del Estado de Sao Paulo (DASP) ${ }^{20}$ función que ejerció hasta 1945-, y cuya oficina pública poseía "cerca de veinte exintegralistas, sendo que os elementos de mais importancia são os senhores Almeida Sales e Lauro Escorrel". ${ }^{21}$ No se puede negar que se creó un nudo alrededor de Reale por haber conseguido cargos a diversos protegidos suyos que le buscaban en virtud de su calidad como Consejero. Esta situación demuestra que existió una verdadera red de cohesión que, pese a los conflictos que amenazaban dañar los lazos de solidaridad entre los integralistas y Vargas, viabilizó la reconstrucción de nuevos lazos que transcendieron los conflictos existentes.

Asimismo otro ejemplo interesante de esta categoría, que podemos llamar red de protección, fue la que surgió en torno a Candido Mota Filho, quien, según información del Departamento de Orden Política y Social (en adelante DOPS), buscó rodearse de auxiliares marxistas, además de recibir frecuentemente a varios intelectuales comunistas militantes en su despacho, como Rafael Sampaio, Francisco Vampré y Mauricio Goulart. ${ }^{22}$ Éste último, a su vez, trabajó en la Revista Diretrizes $^{23}$, donde nombró director a Samuel Wainer. ${ }^{24}$ La revista reunió un grupo de intelectuales simpatizantes y militantes comunistas, lo que supuso una intensa vigilancia por los órganos censores (DIP). Goulart, ${ }^{25}$ además, se relacionó con el sociólogo marxista Caio Prado Jr; que a su vez, gozaba de lazos de identificación con el escritor Dyonelio Machado ${ }^{26}$ y Jorge Amado ${ }^{27}$ (ambos escritores comunistas que participaron de la Alianza Nacional Libertadora, coalición opositora a Vargas).

Si por un lado la pertenencia a un grupo socialmente marginado generó un sentimiento de solidaridad entre ellos comportándose como un grupo más o menos compacto; por el otro, la pertenencia a una red de mayor poder les ofreció una serie de coberturas y beneficios políticos. Los elementos heterogéneos dentro de la red demuestran una actitud de apoyo y alianza (sobre todo por parte de Mota Filho) con otras «comunidades de intelectuales», pese a que sus posiciones políticas fuesen distintas. En este sentido, en torno a los intelectuales dipeanos e integralistas se configuraron complejas redes, cuyos nudos se expandieron para

\footnotetext{
20 El DASP fue dispuesto en la Constitución de 1937 y creado el 30 de julio de 1938. Estuvo directamente subordinado a Getulio Vargas, y tenía el objetivo de profundizar la reforma administrativa destinada a organizar el servicio público del país.

${ }^{21}$ APSP, Prontuario 40682.

${ }^{22}$ APSP, Código 30K4020.

${ }^{23}$ La revista fue cerrada a principios de 1945 por orden del DIP.

${ }^{24}$ Samuel Wainer mantuvo durante los años cincuenta estrechas relaciones con el Presidente Getulio Vargas y fue fundador y editor del periódico Última Hora (1951).

${ }^{25}$ En 1935 se vinculó a la Alianza Nacional de Liberación (ANL). En 1942, fue llevado a la Prisión Casa de Detenção.

${ }^{26}$ Fue detenido en 1935 por participar de la Alianza Nacional Libertadora (ANL). APSP, Prontuario 1691.

${ }^{27}$ Jorge Amado fue encarcelado dos veces, en 1936 y 1945. Posteriormente, se exilió en Uruguay. Fue considerado unos de los más preeminentes intelectuales comunistas del período. APSP, Código 30K.33.227.
} 
crear diferentes tipos de relación, como las que se desplegaron en torno a Reale y Mota Filho. Redes que, por un lado, garantizaron la supervivencia de integralistas tras el conflicto y ruptura con Vargas, y, por el otro, las relativas a los intelectuales comunistas, que se valieron de su capital relacional con Mota para protegerse de la represión estatal.

\section{Gráfico $\mathbf{N}^{\circ} \mathbf{1}^{28}$}

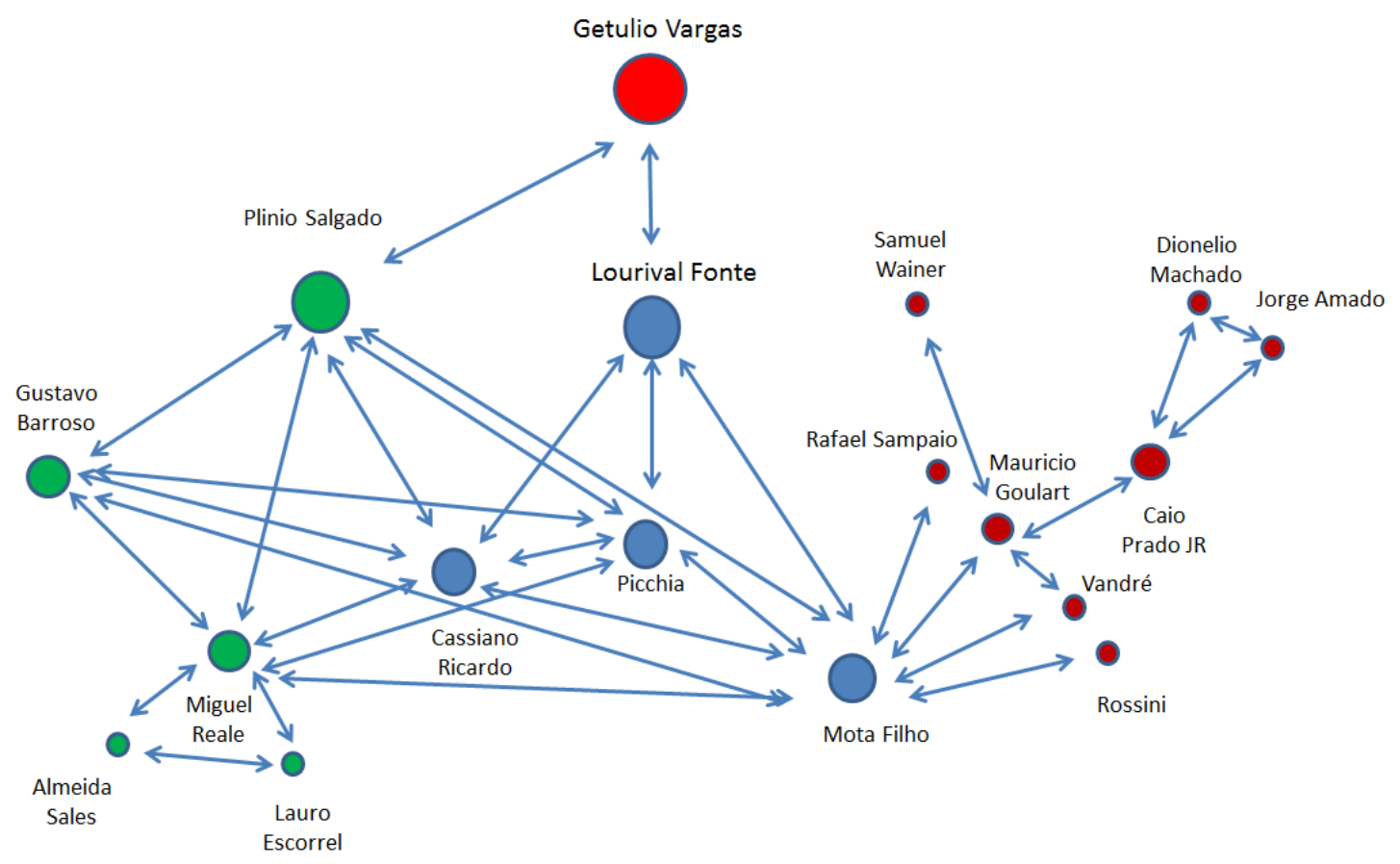

\section{Las redes formadas en torno a Gustavo Capanema}

Es imposible hablar de intelectuales, literatura y cultura durante el Estado Novo sin hacer referencia al ministro de Educación entre 1934 y 1945, Gustavo Capanema. No obstante, la historia de la construcción de las relaciones entre intelectuales y el poder político en la gestión Capanema es anterior a la creación del ministerio. ${ }^{29}$ Se trata por tanto de una nueva generación de escritores y artistas con una identidad más o menos coherente, que tuvieron como antecedentes la experiencia y el estrecho vínculo de camaradería y de colaboración profesional desde los tiempos de sus reuniones en los cafés de la Rua da Bahía, localizados en la ciudad de Belo Horizonte. Entre ellos estaba, además de Capanema, Carlos Drummond, quien sería su futuro jefe de gabinete.

El Estado Novo fue el epicentro de un periodo de reunión de un grupo diverso de intelectuales que participaron en las trincheras estatales. La generación modernista fue la que ocupó la gran mayoría de los cargos públicos, especialmente

\footnotetext{
${ }^{28}$ Gráfico de las redes entre Vargas, Lourival, Plinio y otros intelectuales. Elaboración propia.

29 Helena Bomeny (org.). Constelação Capanema: intelectuais e políticas. Rio de Janeiro, Ed. Fundação Getulio Vargas, 2001; págs. 15-22.
} 


\section{Gabriela De Lima Grecco}

del ministerio de Capanema. Mario de Andrade, Graciliano Ramos, Cecilia Meireles, Érico Verissimo, José Lins do Rego, Carlos Drummond de Andrade o Manuel Bandeira fueron algunas de las personalidades que imprimieron su palabra y espíritu en publicaciones y proyectos oficiales, como en las revistas Atlântico ${ }^{30}$ y Cultura Política, así como en la política pública del libro. Estos escritores fueron capaces de crear una gran red en torno a Capanema, cuyos discursos fueron finalmente vinculados al régimen brasileño.

Con la creación del Instituto Nacional del Libro (en adelante INL) en diciembre de 1937 se dio inicio a una fuerte colaboración entre una rama bastante diversa de intelectuales. El presidente Getulio Vargas nombró como director del INL a Augusto Meyer -intelectual consagrado como literato, ensayista y crítico literario-, contando con la colaboración de los intelectuales que compusieron la llamada "Constelación Capanema», ${ }^{31}$ es decir, la red encabezada por Capanema. Entre los más cercanos a él podemos destacar: Mario de Andrade, jefe de la sección del Diccionario y de la Enciclopedia Brasileña; Sérgio Buarque de Holanda, jefe de la sección de publicaciones; y Carlos Drummond de Andrade, jefe de gabinete del ministro Capanema.

Para el ministro Capanema el libro era la más poderosa creación del genio humano. Su influencia no tenía límites y por ello el Estado debía vigilar que cumpliera su misión inspiradora de las grandes causas humanas. ${ }^{32}$ Para la consecución de este objetivo, la colaboración de los escritores modernistas fue esencial. En diciembre de 1938, el ministro instaló la Comisión Nacional del Libro Didáctico con atribuciones para examinar y seleccionar, entre otros asuntos, la literatura infantil que iba a ser utilizada en las escuelas públicas. Para llevar a cabo tal proyecto, se impulsó un pequeño grupo de escritores, entre los cuales es posible destacar a Manuel Bandeira, José Lins do Rego y Cecilia Meirelles, bajo la coordinación del poeta católico Murilo Mendes. Tras la organización de un concurso de libros infantiles y un intenso debate durante los encuentros del grupo, la comisión definió que la literatura infantil era aquella que daba pie a la imaginación. De esta forma crearon una lista de autores que elaborarían las obras infantiles, entre los que se encontraban José Lins do Rego, Graciliano Ramos y Érico Veríssimo. Todos estos escritores favorecieron la construcción de una red de intelectuales profesional, de compañerismo e, incluso, de amistad.

En este sentido, claro está que las redes se cohesionan a través de lazos estables, como son las de amistad y camaradería. Con estas características fue construida en torno al Ministro de Educación una red que, además de ser política, fue también fraterna. En las cartas intercambiadas entre Mario de Andrade y

\footnotetext{
30 Vid. al respecto: Heloisa Paulo. Estado Novo e propaganda em Portugal e no Brasil: o SPN/SNI e o DIP. Coimbra, Livraria Minerva, 1994.

31 Helena Bomeny (org.). Constelação Capanema... ,Op .Cit.

32 Suely Braga da Silva. O Instituto Nacional do Livro e a institucionalização de organismos culturais no Estado Novo (1937-1945): planos, ideias e realizações, Dissertação (Mestrado em Ciências da Informação). Universidade Federal do Rio de Janeiro. Rio de Janeiro, 1992.
} 
Capanema o entre el ministro y Carlos Drummond de Andrade, la relación de amistad surgida en el espacio burocrático estatal fue evidente. El 23 de febrero de 1939, Mário de Andrade escribió una carta dirigida al ministro, donde apuntaba que "por mais amizade que lhe tenha e liberdade que tome consigo, sempre é certo que diante de você não esqueço nunca o ministro, que me assusta, me diminui e me subalterniza". También Drummond redactó una carta dirigida al ministro de similar contenido, en la cual afirmó la imposibilidad de separar el amigo del "ministro nem ao governo". Desde luego, la cohesión, la camaradería y la reciprocidad que este colectivo de intelectuales revela la construcción y establecimiento de lazos de confianza. Por otro lado, dado que una red se constituye de forma compleja, existen en ellas fronteras poco delimitadas y llenas de matices. En este caso, Andrade y Drummond se sentían incómodos en su relación casi impersonal y horizontal con un político de jerarquía superior, pero a la vez no dejaban de señalar la importancia de su amistad con el ministro.

Una red de amistad también fue construida entre Graciliano Ramos y Getulio Vargas. A pesar de haber sido arrestado en 1935 debido a sus posiciones políticas de izquierda, Graciliano también disfrutó de cargos públicos (trabajó en el DIP y como fiscal de enseñanza). En una carta de la hija de Getulio, Alzira Vargas do Amaral Peixoto,33 ella afirmó que Vargas no conocía al escritor cuando esté fue detenido. Fue José Olympio, 34 famoso editor miembro de las tertulias literarias de los años veinte y treinta, quien intercedió a favor de Graciliano. Años después, éste fue al Palacio do Catete para agradecer su nombramiento como fiscal de enseñanza, uno de los pocos cargos que el presidente era libre de elegir.

La afinidad de intereses entre el Ministerio de Educación, el Presidente y los escritores se organizó, por lo tanto, en forma de red de tal manera que cada nudo que se formaba entre ellos se convertía a la vez en principio de nuevos lazos que representaban y transmitían a los miembros implicados en el anterior. En primer lugar, las que procedían de la relación directa de los intelectuales con el ministro (resultado de los encuentros en los cafés de Belo Horizonte) y las que se formaron en torno a importantes escritores (como Carlos Drummond y Mario de Andrade). En esta relación, los agentes nodales desempeñaron una función importante para la incorporación de otros intelectuales, convirtiéndose en parte destacada de la red. En segundo lugar, se formaron varios nudos que acabaron por prestar apoyo político al ministerio y expandir su zona de influencia.

Importante, asimismo, fue la cimentación de una red de protección en torno a Gustavo Capanema. En algunos documentos relacionados con el escritor Agripino Grieco es evidente la emergencia de un nuevo nudo de auxilio a intelectuales transgresores dentro de la red, cuyo eje central fue Capanema. En 1934, Agripino colaboró con una revista sobre educación nacional editada por el Ministerio de

\footnotetext{
33 Archivo CPDOC/FGV: AVAP vpr ea 1978/1979.

${ }^{34}$ En torno a José Olympio, editor que publicó grandes obras de la literatura brasileña, se crearon estrechos lazos literarios, entre los cuales estaban los escritores Manuel Bandeira, Carlos Drummond y Mario de Andrade.
} 


\section{Gabriela De Lima Grecco}

Educación, ${ }^{35}$ junto a otros intelectuales como Alceu Amoroso Lima, Carlos Drummond y Fernando Magalhães. En este sentido, la relación entre Agripino y Capanema fue cercana. En una carta dirigida al "ministro amigo", Agripino pidió su ayuda para proteger a su amigo Edison Lins "autor de um magnifico estudo de poesia brasileira" (la obra Historia e Crítica da Poesia Brasileira, publicada en 1937). ${ }^{36}$ No obstante, probablemente Agripino también necesitó su ayuda, ya que estuvo involucrado en algunos episodios contra el gobierno, como la celebración de una ponencia para intelectuales, literarios y periodistas en la cual el servicio secreto del DOPS afirmó que Agripino "desviou-se do assunto da palestra, criticando, de forma evasiva, pessoas de destaque do governo"37; o su participación en manifestaciones organizadas por estudiantes de la Facultad de Derecho en septiembre de $1944 .{ }^{38}$

Del mismo modo, Mario de Andrade hizo valer su capital relacional cuando en 1944, a través de un telegrama a Vargas, Rui César Camargo formuló una denuncia contra un escritor y funcionario del DEIP de Sao Paulo, Rossini Camargo Guarnieri, por haber proferido en una conferencia asuntos comunistas. En esta ocasión, el escritor Mario de Andrade le defendió de estas acusaciones; ${ }^{39}$ que sin embargo no fueron las únicas contra él. En una investigación para la Secretaria de Seguridad Pública, Rossini tuvo que defenderse respecto de su poesía Canto de esperança e louvor de Stalingrado. Relató que había enviado su obra a diversos críticos nacionales, incluso al Director del DEIP, ${ }^{40}$ quien le había desaconsejado la publicación en virtud del poema referirse a la Unión Soviética. ${ }^{41}$

En relación a ello, otros funcionarios deipianos también se conectaron en forma de red de protección, resaltando Magno Bosco, Macedo Baeder y Prado Sampaio. Todos ellos fueron acusados de utilizar las propias máquinas Royal del DEIP para imprimir boletines contra el Gobierno. Macedo Baeder tenía en el cajón de su escritorio del despacho del DEIP copias de la poesía Canto de esperança e louvor de Stalingrado de Rossini, y además había utilizado la propia máquina Royal para realizar diversas copias de poesías de Berco Udler, un escritor ruso que había inmigrado a Brasil. Inferimos, a partir de estos documentos, que existió una red de protección entre los deipianos, cuyo principal enlace fue Rossini, actor con mayores hilos de contactos y, posiblemente, de mayor reconocimiento entre sus pares. Ello nos revela que los puntos de resistencia siempre están presentes dentro de la red de poder. La resistencia es ella misma coextensiva al poder, ${ }^{42}$ y necesita también estrategias precisas para organizarse y cimentarse en el campo político. Estos agentes sociales fueron, por lo tanto, capaces de proponer una resistencia dentro

\footnotetext{
35 Conforme el documento GC g 1934.09.07-1.

36 Archivo CPDOC/FGV; GCg 1934.09.07-1.

37 APSP, 20K.65.9

38 APSP, 20K.71.1

${ }^{39}$ Heloisa Paulo. Estado Novo e propaganda...,Op. Cit, pág.162.

40 Deducimos por la información de la documentación analizada que sea Candido Mota Filho.

${ }^{41}$ APSP, Prontuario 40746.

42 Michel Foucault. Microfísica del poder. Madrid, Las ediciones de la Piqueta, 1992.
} 
de los propios aparatos estatales. Desde luego, si no hubiese una complejidad de grupos, movimientos diversos y conflictividad de intereses, la red Capanema no habría sido tan diversa.

\section{Gráfico $\mathbf{N}^{\circ} 2$}

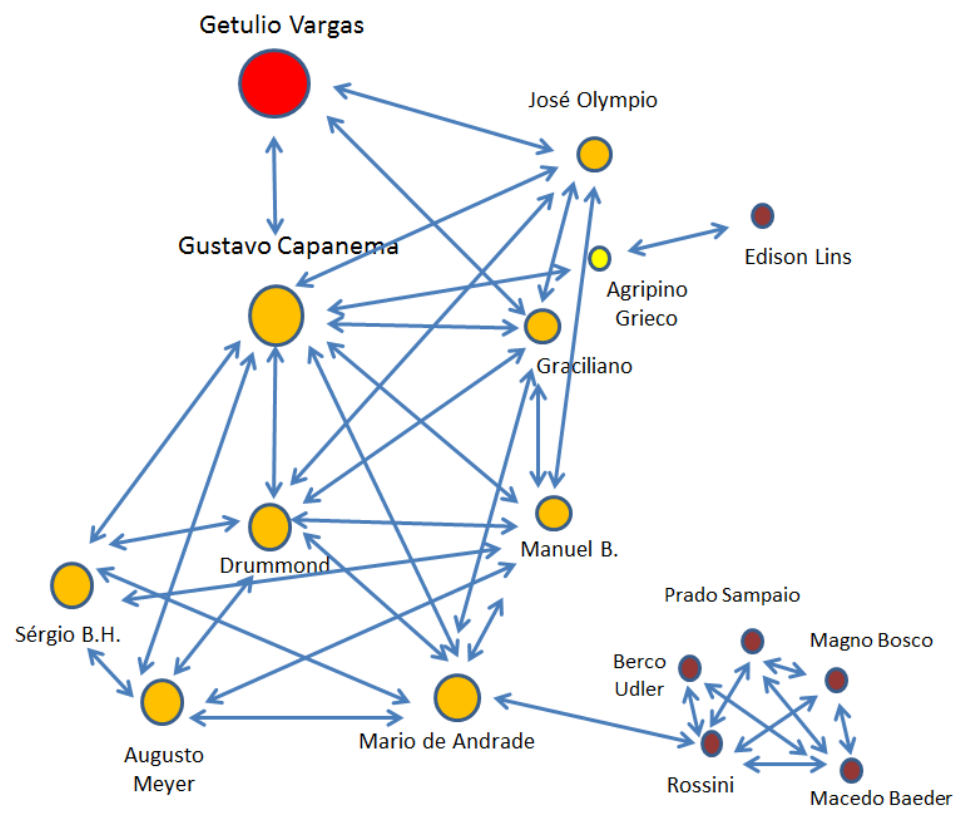

\section{Conclusiones}

A lo largo del presente trabajo nos hemos ocupado de describir las redes de intelectuales, así como sus vínculos personales de amistad y solidaridad. Estos lazos fueron creados a partir de relaciones entre individuos heterogéneos, consolidándose en núcleos sólidos con el paso del tiempo que fueron reforzados por relaciones de amistad, hecho que permitió sustentar las redes. En este sentido, la teoría de las redes no hace referencia al análisis de un grupo como un todo integrado por individuos homogéneos, sino más bien del estudio de los lazos más o menos estables que se construyen a lo largo del tiempo.

Los diferentes grupos de intelectuales que participaron de la burocracia estatal colaboraron con el Estado Novo ejerciendo su influencia en el campo cultural y ayudando a que el régimen sustentara un proyecto ideológico sólido. Si por un lado, el Estado Novo permitió que muchos intelectuales forjasen su carrera, obteniendo una forma de promoción social; por el otro, esta burocracia ilustrada se constituyó como pilar básico del estado, aunque estuvieron obligados a acomodarse dentro de la dinámica de las competencias estatales. En este sentido, los intelectuales brasileños reivindicaron su papel de guías de lo nacional, pasando a ejercer su labor poético-literaria desde los dominios del Estado. Existieron, sin embargo, un amplio y heterogéneo abanico de relaciones.

Así, mientras que los deipeanos construyeron lazos más o menos estables con el poder político disfrutando de altos cargos burocráticos; los integralistas 


\section{Gabriela De Lima Grecco}

tuvieron fracturas en su relación con el régimen que, sin embargo, pudo ser reconstruida a partir de nuevas relaciones de colaboración. Por otro lado, surgieron nuevos lazos en torno a Candido Mota Filho, hecho que contribuyó a la instauración de una red de protección que posibilitó la entrada de «comunistas» en el seno del órgano represor DEIP. Similar a esta red, fue la que se formó en torno a las figuras de Rossini y Agripino Grieco. Estos dos escritores usaron su capital relacional para garantizar una actuación transgresora dentro y fuera de la burocracia estadonovista. Las relaciones de amistad también fueron importantes para delimitar el alcance de las redes, cuyo centro fue el ministro Gustavo Capanema.

Considero que este estudio nos conduce a una mejor comprensión de cómo se estructuraron las distintas relaciones entre el poder y sus agentes, y cuáles fueron las estrategias desarrolladas para que los sujetos se adaptaran a esta nueva coyuntura política-cultural. De esta forma, a través del estudio de esas redes, es posible comprender las relaciones en que se vieron inmersos los actores sociales y la manera en la que penetraron y se sirvieron de las instituciones.

\section{Fuentes}

Archivo CPDOC, Fundação Getulio Vargas (Rio de Janeiro).

Archivo Público de Sao Paulo, Fondo DOPS.

\section{Bibliografia}

Angela Maria de Castro Gomes. $O$ ministro e sua correspondência: projeto político e sociabilidade intelectual, Capanema: o ministro e seu ministério. Rio de Janeiro, FGV, 2000.

Daryle Williams. "Gustavo Capanema, o ministro da Cultura". GOMES, Angela Maria de Castro (org.). Capanema: o ministro e seu ministério. Rio de Janeiro, FGV, 2000; págs.251-269.

. Culture wars in Brazil: the first Vargas Regime, 1930-1945. Durham \& London, Duke University Press, 2001.

Helena Bomeny (org.). Constelação Capanema: intelectuais e políticas. Rio de Janeiro, Ed. Fundação Getulio Vargas, 2001.

Heloisa Paulo. Estado Novo e propaganda em Portugal e no Brasil: o SPN/SNI e o DIP. Coimbra, Livraria Minerva, 1994.

Homi Bhabha. O local da cultura. Belo Horizonte, UFMG, 1998.

Jorge Schwartz. Vanguardas Latino-Americanas: polêmicas, manifestos e textos críticos. São Paulo, EDUSP, 1995.

Juan Pan-Montojo (ed.). "Poderes privados y recursos públicos". Ayer; n66. Madrid, 2007.

Julien Benda. La traición de los intelectuales. Argentina, Efece ediciones, 1974.

Louis Althusser. Ideología y aparatos ideológicos del Estado. Freud y Lacon. Buenos Aires, Nueva visión, 1988. 
Maria José Campos. "Cassiano Ricardo e o "mito da democracia racial": uma versão modernista em movimento”. Revista USP. São Paulo, 2005-2006.

Michel Foucault. Microfísica del poder. Madrid, Las ediciones de la Piqueta, 1992.

Nilolaus Bottcher; Bernd Hausberger; \& Antonio Ibarra (coords.). Redes y negocios globales en el mundo ibérico, siglos XVI-XVIII. Madrid, Iberoamericana, 2011.

Pierre Bourdie. A economia das trocas simbólicas. Sao Paulo, Editora Perspectiva, 1982.

.o poder simbólico. Rio de Janeiro, Bertrand Brasil, 2010.

Randal Johnson. "A Dinâmica do Campo Literário Brasileiro". Revista USP. São Paulo; n²6, junho/agosto, 1995; pág. 161.

Sergio Miceli. Intelectuais à brasileira. São Paulo, Companhia das Letras, 2001.

Simon Schawartzman, Helena Bomeny y Vanda Maria Costa. Tempos de Capanema. Rio de Janeiro, Paz e Terra, 1984.

Suely Braga da Silva. O Instituto Nacional do Livro e a institucionalização de organismos culturais no Estado Novo (1937-1945): planos, ideias e realizações, Dissertação (Mestrado em Ciências da Informação). Universidade Federal do Rio de Janeiro, Rio de Janeiro, 1992.

Tatyana Amaral de Maia. Os cardeais da cultura nacional. São Paulo, Itaú Cultura, 2012.

Recibido: 03/10/2015

Evaluado: $15 / 11 / 2015$

Versión Final: 06/12/2015 